\title{
Continuous Spinal Block as part of Balanced Anaesthesia for Robotic-assisted Major Pancreatic Surgery
}

\author{
F.C. TSAI, K.L. WOON ${ }^{1}$
}

Euroanaesthesi 18 1 Department of Anaesthesia and Surgical Intensive Care, Changi General Hospital, Singapore

\section{Introduction}

- Continuous spinal block provides optimal surgical conditions and maintains cardiorespiratory stability with low doses of local anaesthetics. ${ }^{1}$

- This case report aims to demonstrate its efficiency and safety for complex surgical procedures e.g. robotic-assisted major abdominal surgeries.

\section{Case Report}

- 58 year-old lady $(59 \mathrm{~kg}, 167 \mathrm{~cm})$, diabetes mellitus, hypertension

- Diagnosis: Pancreatic head adenocarcinoma

- Surgery: Robotic-assisted laparoscopic Whipple's procedure

- Pre-induction: Continuous spinal block was performed using 21G Sprotte needle at L3-4 interspace. After obtaining free flow of CSF, $25 \mathrm{G}$ catheter was threaded into subarachnoid space and anchored at $8 \mathrm{~cm}$ at skin. The initial intrathecal (IT) bolus consisted of $0.5 \%$ plain bupivacaine $2.5 \mathrm{mg}$, morphine $200 \mathrm{mcg}$ and fentanyl $15 \mathrm{mcg}$.

- Intraoperative: Remained haemodynamically stable. Further two IT doses of $2.5 \mathrm{ml}$ of $0.1 \%$ bupivacaine each were given after $120 \mathrm{~min}$ and $480 \mathrm{~min}$.

- After 5.5 hours, intraoperative bleeding occurred: Surgery was converted from laparoscopic to open approach. The patient received 1 unit red cells, 500ml fresh frozen plasma and tranexamic acid $1 \mathrm{~g}$. The surgery lasted 9 hours and intraoperative blood loss was about $1 \mathrm{~L}$.

- No long-acting systemic opioid was required.

- During surgical skin closure, IT top-up was done with $0.1 \%$ bupivacaine $2.5 \mathrm{ml}, 100 \mathrm{mcg}$ morphine and $20 \mathrm{mcg}$ fentanyl. Spinal catheter was removed at end of surgery.

- Post-operative: Pain was well controlled without opioids.

- No evidence of infection, neurological deficit or post-dural puncture headache.

\section{Discussion}

- Continuous spinal block is useful for major abdominal surgeries because it causes less haemodynamic disturbance, allows titration of local anaesthetic dose according to surgical needs and provides excellent perioperative analgesia.

- Combining central neuraxial blockade with GA can attenuate stress response to surgery, decrease thromboembolic events and minimize systemic opioids requirement which enhance early postoperative recovery.

\section{Learning Points}

- Continuous spinal block offers reliable and safe perioperative analgesia while maintaining cardiorespiratory stability. This technique could be combined with GA for high risk patients undergoing complex abdominal surgeries. 